\title{
Prevalence of breast-feeding in the Norwegian Mother and Child Cohort Study and health service-related correlates of cessation of full breast-feeding
}

\author{
Anna-Pia Häggkvist ${ }^{1,2}$, Anne Lise Brantsæter ${ }^{1}$, Andrej M Grjibovski ${ }^{3,4,5}$, \\ Elisabet Helsing ${ }^{6}$, Helle Margrete Meltzer ${ }^{1}$ and Margaretha Haugen ${ }^{1, *}$ \\ 'Department of Food Safety and Nutrition, Norwegian Institute of Public Health, PO Box 4404 Nydalen, \\ NO-0403 Oslo, Norway: ${ }^{2}$ National Resource Centre for Breastfeeding, Division of Obstetrics and \\ Gynaecology, Rikshospitalet, Oslo University Hospital, Oslo, Norway: ${ }^{3}$ Department of Infectious Diseases \\ Epidemiology, Norwegian Institute of Public Health, Oslo, Norway: ${ }^{4}$ International School of Public Health, \\ Northern State Medical University, Arkhangelsk, Russia: ${ }^{5}$ Institute of Community Medicine, \\ University of Tromsø, Tromsø, Norway: ${ }^{6}$ Former Regional Officer for Nutrition, WHO, Copenhagen, Denmark
}

Submitted 28 October 2009: Accepted 17 May 2010: First published online 25 June 2010

\begin{abstract}
Objective: First, to describe the prevalence of both full and partial breast-feeding during the first 6 months; second, to study the associations between selected health service-related factors and cessation of full breast-feeding at three time intervals.

Design: Retrospective questionnaires, 6 months after birth.

Setting: The Norwegian Mother and Child Cohort Study (MoBa).

Subjects: In total, 29621 women.

Results: While $96 \cdot 6 \%, 94 \cdot 0 \%, 90 \cdot 8 \%, 86 \cdot 9 \%, 83 \cdot 8 \%$ and $80 \cdot 0 \%$ of the infants were breast-fed at 1, 2, 3, 4, 5 and 6 months, respectively, the corresponding proportions for full breast-feeding were $84 \cdot 6 \%, 79 \cdot 1 \%, 70 \cdot 9 \%, 44 \cdot 0 \%, 16 \cdot 7 \%$ and $2 \cdot 1 \%$. An increased risk of cessation of full breast-feeding during the first month was associated with supplementation during the first week of life with water (relative risk (RR) 1.77; 95\% CI 1.52, 2.06), sugar water (RR 1.73; 95\% CI 1.49, $2 \cdot 00)$ or formula (RR 5.99; $95 \%$ CI 5.58, 6.42). An increased risk was also associated with Caesarean delivery (RR 1.08; 95\% CI 1.00, 1.16) and breast-feeding problems (RR 1.56; 95\% CI 1.45, 1.67). Between months 1 and 3, the risk of cessation of full breast-feeding remained elevated in the case of supplementation during the first week of life with water (RR 1.29; 95\% CI 1·14, 1.45), sugar water (RR 1.48; 95\% CI 1.34, 1.64) or formula (RR 1·18; 95\% CI 1·07, 1.29). The same applied to Caesarean delivery (RR 1.15; $95 \%$ CI 1·06, 1.25).

Conclusions: Supplementation during the first week, breast-feeding problems and Caesarean delivery are associated with early cessation of full breast-feeding. The results support a cautious approach to supplementation during the first week of life.
\end{abstract}

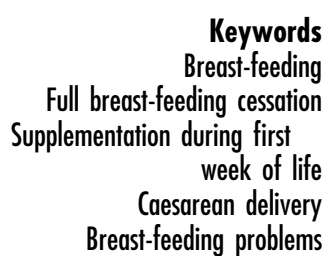

Breast-feeding, and in particular exclusive breast-feeding as defined in Table 1, provides optimal infant nutrition $^{(1-3)}$. Human milk contains numerous immunological components that directly protect infants. Studies have shown that exclusive breast-feeding reduces the risk of infectious diseases in the respiratory, gastrointestinal and urinary tracts ${ }^{(4-8)}$, and that it protects premature children from neonatal sepsis and necrotizing enterocolitis ${ }^{(9-11)}$. In addition, the immunological components of human milk support the development and maturation of the infant's own immune system, which may explain some of the longterm health benefits observed in breast-fed children ${ }^{(12)}$. Recent studies have also indicated long-term health benefits of lactation for the mother, such as a reduced risk of breast cancer $^{(1,2)}$.

Breast-feeding is influenced by a variety of factors. These include sociodemographic, biomedical, health servicerelated, psychosocial and cultural factors, as well as public breast-feeding policy ${ }^{(13,14)}$. The factors associated with cessation of any breast-feeding are well documented ${ }^{(14-16)}$, while less is known about the factors associated with the cessation of exclusive breast-feeding and full breastfeeding. Fully breast-fed infants are defined as those who are either exclusively breast-fed or who receive waterbased supplementation, but no solid food or formula (Table 1). Current WHO recommendations ${ }^{(3)}$ highlight 
Table 1 Definitions of breast-feeding based on WHO definitions ${ }^{(53,54)}$

\begin{tabular}{|c|c|c|c|}
\hline Exclusive breast-feeding & $\begin{array}{l}\text { Must receive breast milk but may receive ORS, drops, } \\
\text { syrups, vitamins, minerals or medicines } \\
\text { Cannot receive solid or semi-solid foods, formula or other } \\
\text { non-human milk or water/water-based drinks/fruit juices, } \\
\text { daily or weekly }\end{array}$ & \multirow{3}{*}{ Full breast-feeding } & \multirow{3}{*}{ Any breast-feeding } \\
\hline Predominant breast-feeding & $\begin{array}{l}\text { Must receive breast milk and water, water-based drinks or } \\
\text { fruit juices, and may receive ORS, drops, syrups, } \\
\text { vitamins, minerals or medicines } \\
\text { Cannot receive solid or semi-solid foods, formula or other } \\
\text { non-human milk, daily or weekly }\end{array}$ & & \\
\hline Partial breast-feeding* & $\begin{array}{l}\text { Must receive breast milk combined with either solid or } \\
\text { semi-solid foods, formula or other non-human milk }\end{array}$ & & \\
\hline
\end{tabular}

ORS, oral rehydration salt.

*Partial breast-feeding is similar to 'complementary feeding' in the WHO document ${ }^{(54)}$.

the desirability of 6 months of exclusive breast-feeding. This necessitates studies of the factors associated with the cessation of exclusive or full breast-feeding.

The Norwegian health authorities recommend exclusive breast-feeding for the first 6 months of life, echoing the WHO recommendation ${ }^{(3,17)}$. Almost all mothers in Norway initiate breast-feeding $(98 \%)^{(18)}$. Some $80 \%$ still breast-feed at 6 months, but only $9 \%$ do so exclusively. The largest decrease in exclusive breast-feeding, from $63 \%$ to $46 \%$, occurs between 3 and 4 months ${ }^{(18)}$.

Early supplementation with infant formula, water or water-based supplements like sugar water is associated with a shorter duration of exclusive or full breastfeeding ${ }^{(8,19-23)}$. However, supplementation with water or sugar water has been studied less than formula supplementation $^{(19,20,22)}$. Knowledge about the possible influence of other health service-related factors is limited. Few studies have reported associations between the duration of exclusive or full breast-feeding and breastfeeding problems, transfer to a neonatal intensive care unit (NICU) or the size of the birth institution ${ }^{(24-27)}$. In addition, studies investigating the association between delivery by Caesarean section (CS) and cessation of exclusive or full breast-feeding have also been inconclusive $^{(23,24,28)}$.

To the best of our knowledge, no previous study has examined the association between these health servicerelated factors and cessation of full breast-feeding among mothers who are still breast-feeding. Moreover, many previous studies have ignored the fact that these associations may differ at different points in time during the first 6 months after birth. The Norwegian Mother and Child Cohort Study (MoBa), a large, prospective pregnancy cohort, enables examination of both issues.

The objectives of the present study were: (i) to describe the prevalence of full and partial breast-feeding during the first 6 months in mothers participating in MoBa; and (ii) to study the associations between health servicerelated factors and cessation of full breast-feeding among mothers still breast-feeding at three different time intervals during the first 6 months.

\section{Materials and methods}

\section{Study population and sample}

The data set is part of the MoBa cohort, initiated and maintained by the Norwegian Institute of Public Health. In brief, MoBa is a pregnancy cohort that in the years from 1999 to 2008 has included $~ 107000$ pregnancies. Women were recruited to the study through a postal invitation in connection with a routine ultrasound examination offered to all pregnant women in Norway during weeks 17-18 of gestation. The participation rate was $43 \%{ }^{(29)}$. Three questionnaires (Q1-Q3) were completed during pregnancy, and the first questionnaire after birth (Q4) was completed at 6 months. The respective response rates for questionnaires Q1-Q4 were 95\%, 93\%, 92\% and 97\%. The self-completed questionnaires covered health, chemical and physical factors in the environment, nutrition, lifestyle and background factors $^{(29)}$ (the questionnaires may be downloaded from http://www.fhi.no). The cohort database is linked to the Medical Birth Registry of Norway $(\mathrm{MBRN})^{(30)}$. The study was approved by the Regional Committee for Ethics in Medical Research and the Norwegian Data Inspectorate ${ }^{(29)}$.

At the time of the present analysis, Q4 was available for 40805 mother-infant pairs (taken from the qualityassured data file (version 3) made available for research in 2007). Our study sample included all participants who had answered both Q1 and version b of Q4. The infants were born during the period 2002-2005. Triplets and second twins were excluded. Pairs of twins were represented by twin 1 . There was no difference in breast-feeding prevalence between twin 1 and twin 2 during the first 6 months (all $P>0 \cdot 05$ ). Mothers who did not answer all questions about infant nutrition (questions 15-18 in Q4) were excluded, resulting in a final sample of 29621 (Fig. 1).

\section{Variables}

The breast-feeding data are based on three questions about infant nutrition in Q4. The questions were asked retrospectively 6 months after birth. The first question asked about infant feeding during the first week after birth and offered the following alternatives: 'breast milk', 


Participants included in
breast-feeding
prevalence (Fig. 2)
Participants who
initiated breast-feeding
(Table 2)
Breast-feeding at 0
month and still breast-
feeding at 1 month
(Table 3)
Full breast-feeding at 1
month and still breast-
feeding at 3 months
(Table 4)
Full breast-feeding at 3
months and still breast-
feeding at 6 months
(Table 5)

Participants included in breast-feeding prevalence (Fig. 2)

Participants who initiated breast-feeding (Table 2) month and still breastfeeding at 1 month (Table 3)

Full breast-feeding at 1 month and still breast feeding at 3 months months and still breast(Table 5)

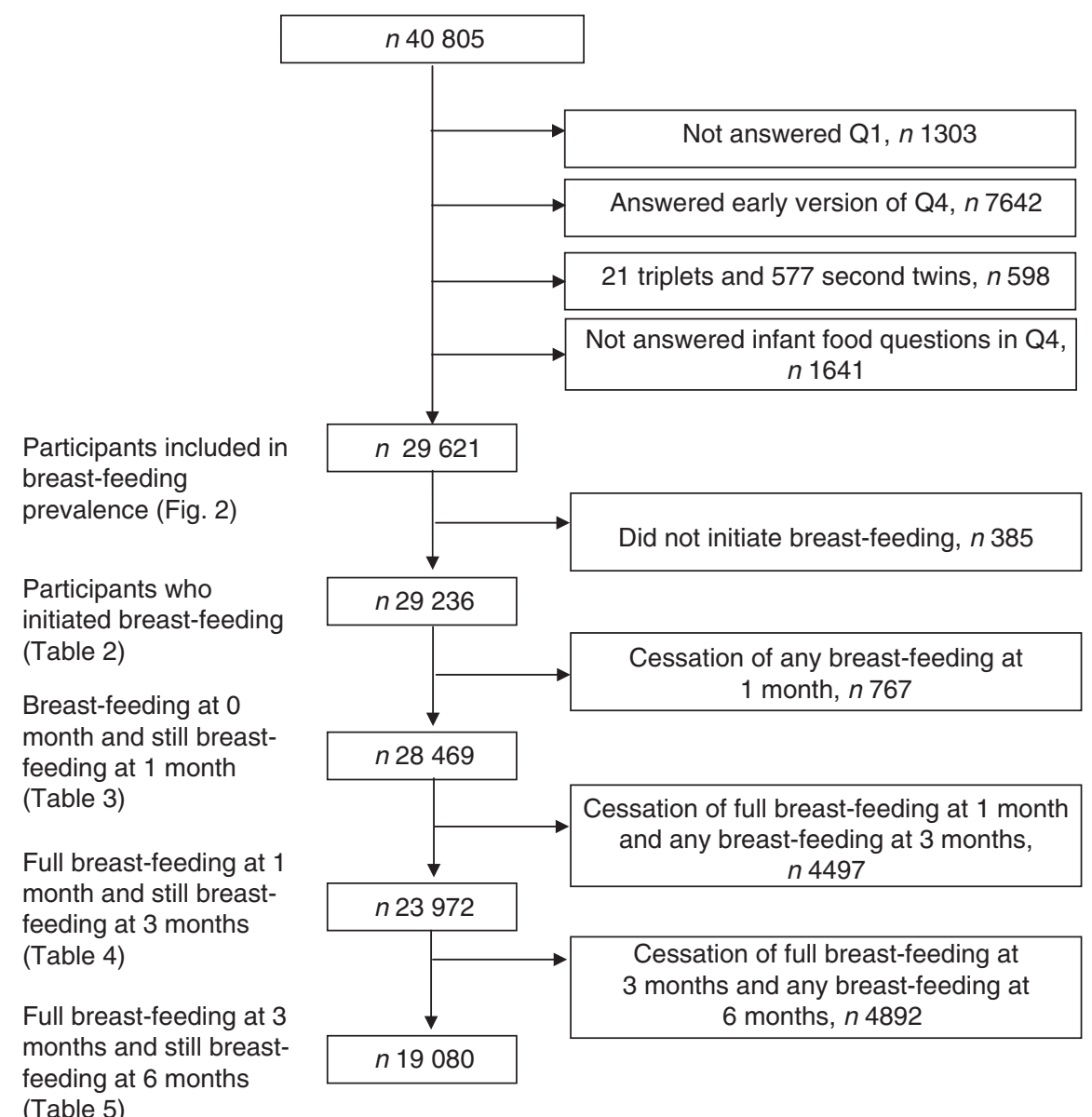

Fig. 1 Flow diagram for inclusion of participants for the study from the Norwegian Mother and Child Cohort

'water', 'sugar water', 'infant formula', 'other' and 'don't know'. The second question was: 'What kind of milk did your baby receive at months $0,1,2,3,4,5$ and 6?' The possible answers were: 'breast milk', 'formula' and 'other milk'. For both of these questions more than one liquid could be marked. The last question was: 'In which month did you start giving complementary food to the child?' The answers to this final question covered seventeen different food items, which were collapsed into one complementary food variable.

The breast-feeding categories used in the present study were based on WHO definitions (Table 1). The category 'exclusive breast-feeding' could only be studied the first week of life, as the use of water, water-based drinks and fruit juice in the period $0-5$ months was not included in all versions of the questionnaire. The 'full breast-feeding' variable used in the regression analysis describes infant feeding 'since birth', except for supplementation during the first week of life. In the present article, 'breast-feeding' must be understood as 'breast milk feeding', as no data were available on the feeding practice.

The following health service-related factors were investigated: (i) use of supplementation during the first week of life; (ii) CS delivery; (iii) breast-feeding problems; (iv) transfer to NICU; and (v) size of birth institution. Data about the use of supplements during the first week of life and breast-feeding problems are derived from Q4. Information on CS delivery, transfer to NICU and size of birth institution are taken from the MBRN. Breast-feeding problems for which health personnel were contacted during the first month after birth were combined into a dichotomous variable, which was coded as 'no' if there were no problems and 'yes' if the mother reported (i) mastitis, (ii) sore nipples or (iii) other undefined breast-feeding problems. The breast-feeding problems were of such severity that health personnel were contacted during the first month after birth. Supplementation during the first week of life was classified into four categories: 'only breast milk', 'breast milk and water', 'breast milk and sugar water' and 'breast milk and infant formula'. Five categories were offered for size of institution (number of births per year): <500, 500-1499, 1500-2999, >3000 and unknown. Three categories were offered for transfer to NICU: 'no', 'yes' and 'unknown', while delivery method was assessed by reference to a dichotomous variable: 'vaginal' or 'Caesarean section'.

Pre-pregnancy BMI and smoking status were derived from Q1, administered in weeks $17-18$ of gestation. 
Educational level, household income, smoking status during lactation and marital status were derived from Q4. Birth year, sex and birth weight of the infant, plurality, maternal age, parity and place of residence were obtained from the $\mathrm{MBRN}^{(30)}$. Birth-weight data not available from the MBRN ( $n 72$ ) were calculated using data taken from maternal reports in Q4. We used data on smoking during pregnancy in the analysis of full breast-feeding cessation during the first two time intervals, and for the full breastfeeding cessation between 3 and 6 months we used smoking data from Q4.

\section{Statistical analysis}

Pearson's $\chi^{2}$ test was used to test for differences between proportions. Multivariable Poisson regression with robust variance estimates was used to calculate relative risk (RR) with $95 \%$ confidence interval for cessation of full breastfeeding, at the different time intervals and for all health service-related factors, with and without adjustment for maternal age, maternal education, smoking, marital status, region of birth, household income, birth year, pre-pregnancy BMI, parity, sex of the infant, birth weight and plurality.

We first examined the associations between the selected health service-related factors and cessation of full breastfeeding, for each month. Due to the similarity of the findings for months 1 to 6 (data not shown), only three outcomes were selected: cessation of full breast-feeding during the first month, cessation in the time interval between months 1 and 3 , and cessation in the time interval between months 3 and 6 . Only mothers fully breast-feeding at month 1 were included in the second regression analysis (Table 4), and only the mothers fully breast-feeding at month 3 were included in the third regression analysis (Table 5). The criteria for inclusion in the groups are shown in Fig. 1.

All analyses were performed using the SPSS statistical software package version 14 (SPSS Inc., Chicago, IL, USA). Poisson regression was analysed using the STATA statistical software package version 10 (StataCorp, College Station, TX, USA).

\section{Results}

Participants who were excluded for not having answered the infant feeding questions ( $n$ 1641) did not differ from the other participants with regard to maternal characteristics, but were more likely to be smokers $(P=0 \cdot 019)$.

The prevalence of full breast-feeding during the first week was $81.7 \%$ ( $n$ 24210). The proportion of those exclusively breast-feeding was $70 \cdot 5 \%$ ( $n$ 20.872), while $11 \cdot 3 \%$ ( $n$ 3338) were predominantly breast-feeding. Among those who did not fully breast-feed, $17 \cdot 0 \%$ ( $n$ 5026) were partially breast-feeding and $1.3 \%$ ( $n$ 385) were not breast-feeding at all.

The women who did not initiate breast-feeding ( $n$ 385) exhibited lower educational level, higher pre-pregnancy
BMI, greater incidence of smoking, greater number of CS deliveries, greater number of twin births and lower infant birth weights than the women who initiated breast-feeding. No differences were found with regard to maternal age, household income, parity and infant gender (Table 2).

While $80.0 \%$ of the children were breast-fed at 6 months, only $2 \cdot 1 \%$ were fully breast-fed at this point in time. There was a pronounced decline in full breast-feeding starting from 3 months, with a $26.9 \%$ decline (from $70.9 \%$ to $44.0 \%$ ) between 3 and 4 months and a further $27 \cdot 3 \%$ decline (from $44 \cdot 0 \%$ to $16 \cdot 7 \%$ ) between 4 and 5 months (Fig. 2).

An increased risk of cessation of full breast-feeding during the first month of life was associated with supplementation with water, sugar water or formula during the first week of life, CS delivery and breast-feeding problems, but not institution size. Transfer to NICU was associated with a lower risk. Supplementation with formula was associated with a sixfold risk of cessation of full breast-feeding during the first month (RR 5.99; $95 \%$ CI 5.58, 6.42; Table 3).

CS delivery and supplementation with water, sugar water or formula during the first week of life were still associated with an increased risk of cessation of full breast-feeding in the time interval between months 1 to 3 . The greatest risk was associated with supplementation with sugar water during the first week of life (RR 1.48; $95 \%$ CI 1·34, 1·64; Table 4).

Supplementation with water or sugar water during the first week was still associated with the risk of cessation of full breast-feeding in the time interval between months 3 to 6 (RR $1 \cdot 02 ; 95 \%$ CI $1 \cdot 01,1 \cdot 02$; Table 5 ).

\section{Discussion}

The key finding of the present study is the association between supplementary feeding with formula, water or sugar water during the first week of life and the increased risk of cessation of full breast-feeding, not only during the first month but also in months 1 to 3 of life.

The main strengths of the study include the large sample size and the link to the MBRN. Participants were recruited from both urban and rural regions, and represented all age and socio-economic groups. Further, the study enables the investigation of important factors associated with the cessation of full breast-feeding, as well as adjustment for various confounders. In contrast to most other studies of cessation of full breast-feeding, we studied health servicerelated factors by reference to mothers who were still breast-feeding. Moreover, our examination of the associations of these factors for different time intervals after birth differs from most other studies, which presented hazard ratios during the first 6 months. Proportionality of hazards during the whole period of observation is a necessary assumption for such analyses, which was not the case in 
Table 2 Sample characteristics of mothers by reference to breast-feeding initiation in the Norwegian Mother and Child Cohort Study, 2002-2005

\begin{tabular}{|c|c|c|c|c|c|c|c|}
\hline & \multicolumn{2}{|c|}{$\begin{array}{l}\text { All participants } \\
\quad(n 29621)\end{array}$} & \multicolumn{2}{|c|}{$\begin{array}{l}\text { Did not initiate breast-feeding } \\
(n \text { 385) }\end{array}$} & \multicolumn{2}{|c|}{$\begin{array}{l}\text { Initiated breast-feeding } \\
(n 29236)\end{array}$} & \multirow[b]{2}{*}{$P^{*}$} \\
\hline & $n$ & $\%$ & $n$ & $\%$ & $n$ & $\%$ & \\
\hline \multicolumn{7}{|l|}{ Age (years) } & 0.324 \\
\hline$\leq 24$ & 3274 & $11 \cdot 1$ & 42 & $10 \cdot 9$ & 3232 & $11 \cdot 1$ & \\
\hline $25-34$ & 21025 & $71 \cdot 0$ & 260 & $67 \cdot 5$ & 20765 & $71 \cdot 0$ & \\
\hline$\geq 35$ & 4598 & $15 \cdot 5$ & 72 & $18 \cdot 7$ & 4526 & $15 \cdot 5$ & \\
\hline Missing & 724 & $2 \cdot 4$ & 11 & $2 \cdot 9$ & 713 & $2 \cdot 4$ & \\
\hline \multicolumn{7}{|l|}{ Education (years) } & $<0.001$ \\
\hline$\leq 12$ & 11545 & $39 \cdot 0$ & 203 & $52 \cdot 7$ & 11342 & $38 \cdot 8$ & \\
\hline $13-15$ & 12246 & $41 \cdot 3$ & 124 & $32 \cdot 2$ & 12122 & $41 \cdot 5$ & \\
\hline$\geq 16$ & 5177 & $17 \cdot 5$ & 45 & $11 \cdot 7$ & 5132 & $17 \cdot 6$ & \\
\hline Missing & 653 & $2 \cdot 2$ & 13 & $3 \cdot 4$ & 640 & $2 \cdot 2$ & \\
\hline \multicolumn{7}{|l|}{ Pre-pregnancy BMI $\left(\mathrm{kg} / \mathrm{m}^{2}\right)$} & $<0.001$ \\
\hline$<18.5$ & 812 & $2 \cdot 7$ & 15 & 3.9 & 797 & $2 \cdot 7$ & \\
\hline $18 \cdot 5-24 \cdot 9$ & 18436 & $62 \cdot 2$ & 167 & $43 \cdot 4$ & 18269 & $62 \cdot 5$ & \\
\hline $25 \cdot 0-29 \cdot 9$ & 6581 & $22 \cdot 2$ & 111 & $28 \cdot 8$ & 6470 & $22 \cdot 1$ & \\
\hline$\geq 30 \cdot 0$ & 2910 & $9 \cdot 8$ & 80 & $20 \cdot 8$ & 2830 & $9 \cdot 7$ & \\
\hline Missing & 882 & $3 \cdot 0$ & 12 & $3 \cdot 1$ & 870 & $3 \cdot 0$ & \\
\hline \multicolumn{7}{|l|}{ Smoking during pregnancy } & $<0.001$ \\
\hline Non-smokers & 26528 & $89 \cdot 6$ & 321 & $83 \cdot 4$ & 26207 & $89 \cdot 6$ & \\
\hline Occasional smokers & 931 & $3 \cdot 1$ & 16 & $4 \cdot 2$ & 915 & $3 \cdot 1$ & \\
\hline Daily smokers & 1954 & $6 \cdot 6$ & 45 & $11 \cdot 7$ & 1909 & $6 \cdot 5$ & \\
\hline Missing & 208 & 0.7 & 3 & 0.8 & 205 & 0.7 & \\
\hline \multicolumn{7}{|l|}{ Household income (NOK) } & 0.403 \\
\hline$<500000$ & 7357 & $24 \cdot 8$ & 105 & $27 \cdot 3$ & 7252 & $24 \cdot 8$ & \\
\hline$\geq 500000$ & 19726 & $66 \cdot 6$ & 244 & $63 \cdot 4$ & 19482 & $66 \cdot 6$ & \\
\hline Missing & 2538 & 8.6 & 36 & $9 \cdot 4$ & 2502 & $8 \cdot 4$ & \\
\hline \multicolumn{7}{|l|}{ Parity } & $0 \cdot 106$ \\
\hline 0 & 13228 & $44 \cdot 7$ & 192 & $49 \cdot 9$ & 13036 & $44 \cdot 6$ & \\
\hline 1 & 10604 & $35 \cdot 8$ & 128 & $33 \cdot 2$ & 10476 & $35 \cdot 8$ & \\
\hline \multirow{2}{*}{\multicolumn{7}{|c|}{ Method of delivery }} & \\
\hline & & & & & & & $<0.001$ \\
\hline Vaginal & 25696 & $86 \cdot 7$ & 272 & $70 \cdot 6$ & 25424 & $87 \cdot 0$ & \\
\hline Caesarean section & 3925 & $13 \cdot 3$ & 113 & $29 \cdot 4$ & 3812 & $13 \cdot 0$ & \\
\hline \multicolumn{7}{|l|}{ Gender of the infant } & 0.381 \\
\hline Boy & 14632 & $49 \cdot 4$ & 177 & $46 \cdot 0$ & 14455 & $49 \cdot 5$ & \\
\hline Girl & 14265 & $48 \cdot 2$ & 197 & $51 \cdot 2$ & 14068 & $48 \cdot 1$ & \\
\hline Missing & 724 & $2 \cdot 4$ & 11 & $2 \cdot 9$ & 713 & $2 \cdot 4$ & \\
\hline \multicolumn{7}{|l|}{ Plurality } & $<0.001$ \\
\hline Single child & 29055 & $98 \cdot 1$ & 368 & $95 \cdot 6$ & 28687 & $98 \cdot 1$ & \\
\hline Twins & 566 & 1.9 & 17 & $4 \cdot 4$ & 549 & $1 \cdot 9$ & \\
\hline \multicolumn{8}{|l|}{ Birth weight (g) } \\
\hline$>2500$ & 28600 & $96 \cdot 6$ & 319 & $82 \cdot 9$ & 28281 & $96 \cdot 7$ & $<0.001$ \\
\hline$\leq 2500$ & 1021 & $3 \cdot 4$ & 66 & $17 \cdot 1$ & 955 & $3 \cdot 3$ & \\
\hline
\end{tabular}

${ }^{*} P$ value calculated using Pearson's $\chi^{2}$ test.

the present study. In addition, the use of risk ratios facilitates better interpretation of the results and avoids overestimation of the risk when events are common, which might be the case when logistic regression is used and when results are presented as odds ratios ${ }^{(31)}$.

A limitation of the present study was the retrospective approach, which implied a 6-month recall of infant nutrition. The long recall period may have caused overestimation of the duration of full breast-feeding ${ }^{(32)}$. However, Merten et al. reported no differences in the proportion of fully breast-fed infants when comparing $24 \mathrm{~h}$ recall and retrospective data ${ }^{(19)}$. Finally, we cannot rule out the possibility that unmeasured confounders may have influenced the associations.

The participation rate in $\mathrm{MoBa}$ is only $43 \%{ }^{(29)}$. The potential bias due to self-selection in MoBa was recently evaluated by Nilsen et al. $^{(33)}$; no statistically relative differences in association measures were found between participants and the total population regarding eight exposure-outcome associations evaluated.

The primary aim of the present study was to describe breast-feeding prevalence in the MoBa cohort. The findings regarding initiation of breast-feeding and breastfeeding prevalence closely mirror the findings made in the representative Norwegian Infant Nutrition Survey (SPEDKOST) of children born in $1998^{(34)}$.

SPEDKOST ( $n$ 2383) also employed retrospective questionnaires administered 6 months after birth to collect data on infant nutrition. However, it reported on 'exclusive breast-feeding', which was defined as including water and thus differs slightly from 'full breast-feeding' as used in the present study. In SPEDKOST, the prevalence 


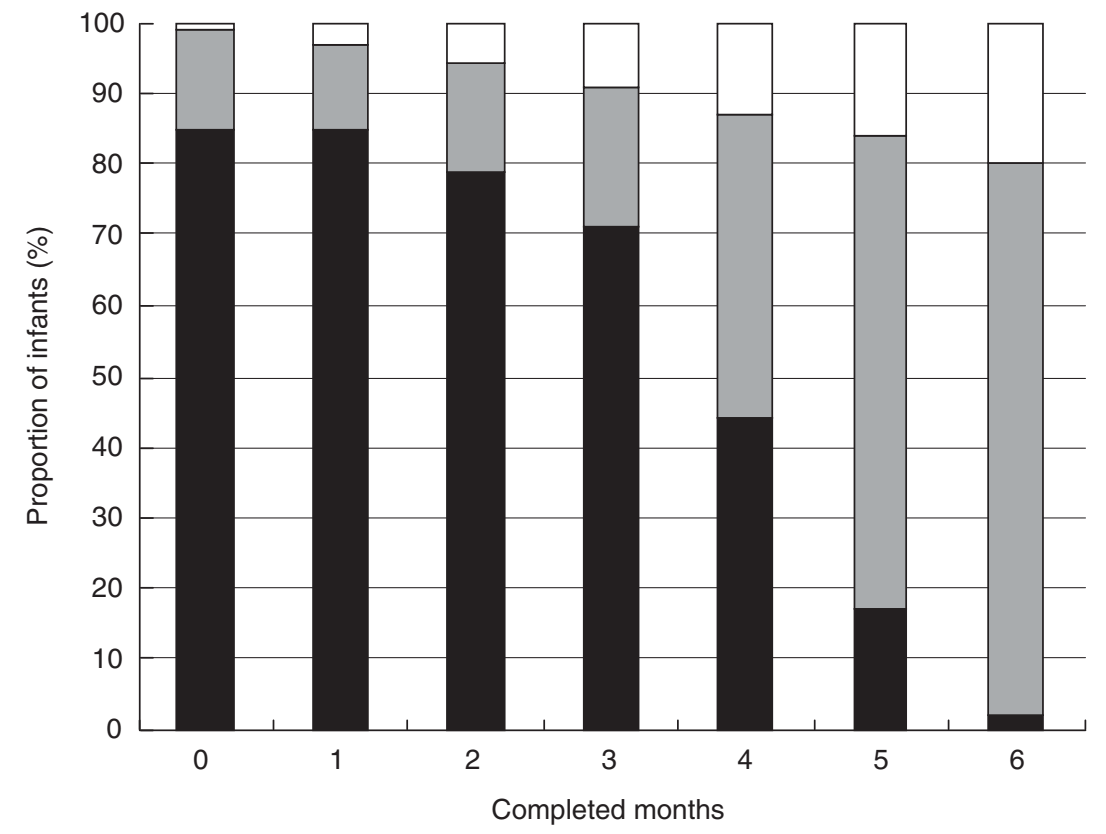

Fig. 2 Prevalence of full ( $\square$ ), partial $(\square)$ and no breast-feeding ( $\square$ ) during the 6 months after birth for 29621 women in the Norwegian Mother and Child Cohort Study, 2002-2005

Table 3 Health service-related factors and cessation of full breast-feeding in mothers still breast-feeding during the first month after birth (total $n$ 28469), Norwegian Mother and Child Cohort Study, 2002-2005

\begin{tabular}{|c|c|c|c|c|c|c|c|c|}
\hline & \multirow[b]{2}{*}{$n$} & \multirow[b]{2}{*}{$\%$} & \multicolumn{2}{|c|}{ Cessation of full breast-feeding } & \multirow[b]{2}{*}{ Crude RR } & \multirow[b]{2}{*}{$95 \% \mathrm{Cl}$} & \multirow[b]{2}{*}{ Adjusted $\mathrm{RR}^{*}$} & \multirow[b]{2}{*}{$95 \% \mathrm{Cl}$} \\
\hline & & & $n$ & $\%$ & & & & \\
\hline \multicolumn{9}{|l|}{ Infant feeding first week } \\
\hline Only breast milk & 20555 & $72 \cdot 2$ & 1259 & $6 \cdot 1$ & 1.00 & Reference & 1.00 & Reference \\
\hline Breast milk and water & 1520 & $5 \cdot 3$ & 168 & $11 \cdot 1$ & $1 \cdot 80$ & $1 \cdot 54,2 \cdot 10$ & $1 \cdot 77$ & $1 \cdot 52,2 \cdot 06$ \\
\hline Breast milk and sugar watert & 1960 & $6 \cdot 2$ & 188 & $10 \cdot 7$ & $1 \cdot 74$ & $1.51,2.02$ & $1 \cdot 73$ & $1 \cdot 49,2 \cdot 00$ \\
\hline Breast milk and formulał & 4636 & $16 \cdot 3$ & 1877 & $40 \cdot 5$ & $6 \cdot 61$ & $6 \cdot 20,7 \cdot 05$ & $5 \cdot 99$ & $5 \cdot 58,6 \cdot 42$ \\
\hline \multicolumn{9}{|l|}{ Delivery method } \\
\hline Vaginal & 24837 & $87 \cdot 1$ & 2819 & $11 \cdot 4$ & 1.00 & Reference & 1.00 & Reference \\
\hline Caesarean section & 3632 & $12 \cdot 9$ & 673 & $18 \cdot 5$ & $1 \cdot 63$ & $1 \cdot 51,1 \cdot 76$ & 1.08 & $1 \cdot 00,1 \cdot 16$ \\
\hline \multicolumn{9}{|c|}{ Breast-feeding problems first month } \\
\hline No & 24784 & $87 \cdot 2$ & 2757 & $11 \cdot 1$ & 1.00 & Reference & 1.00 & Reference \\
\hline Yes & 3685 & $12 \cdot \overline{9}$ & 735 & $19 \cdot 9$ & 1.79 & $1.67,1.93$ & 1.56 & $1.45,1.67$ \\
\hline \multicolumn{9}{|l|}{ Transfer to NICU } \\
\hline No & 24228 & $85 \cdot 1$ & 2912 & $12 \cdot 0$ & 1.00 & Reference & $1 \cdot 00$ & Reference \\
\hline Yes & 2261 & $7 \cdot 9$ & 374 & $16 \cdot 5$ & $1 \cdot 38$ & $1 \cdot 25,1 \cdot 52$ & 0.75 & $0.68,0.83$ \\
\hline Unknown & 1980 & $7 \cdot 0$ & 206 & $10 \cdot 4$ & $0 \cdot 87$ & $0.76,0.99$ & $0 \cdot 86$ & $0.75,0.98$ \\
\hline \multicolumn{9}{|l|}{ Size of institution (births per year) } \\
\hline$<500 \S$ & 3439 & $12 \cdot 1$ & 357 & $10 \cdot 4$ & $1 \cdot 00$ & Reference & $1 \cdot 00$ & Reference \\
\hline $500-1499$ & 7517 & $26 \cdot 4$ & 939 & $12 \cdot 5$ & $1 \cdot 20$ & $1 \cdot 07,1 \cdot 35$ & $1 \cdot 08$ & $0.97,1 \cdot 22$ \\
\hline 1500-2999 & 5416 & $19 \cdot 0$ & 711 & $13 \cdot 1$ & $1 \cdot 30$ & $1 \cdot 12,1 \cdot 43$ & 1.05 & $0.92,1.20$ \\
\hline$>3000$ & 7456 & $26 \cdot 2$ & 909 & $12 \cdot 2$ & $1 \cdot 17$ & $1 \cdot 05,1 \cdot 32$ & 1.03 & $0.90,1 \cdot 16$ \\
\hline Unknown & 4641 & $16 \cdot 3$ & 576 & $12 \cdot 4$ & $1 \cdot 20$ & $1 \cdot 06,1 \cdot 35$ & 1.45 & $0.87,2 \cdot 40$ \\
\hline
\end{tabular}

RR, relative risk; NICU, neonatal intensive care unit.

*Adjusted for the other variables in the table and maternal age, maternal education, smoking during pregnancy, marital status, region of birth, household income, birth year, pre-pregnancy BMI, parity, sex of the infant, birth weight and plurality.

tSugar water could include water.

¥Formula-fed could include sugar and/or water.

§Including 207 births outside institution.

of full breast-feeding was only 1-2\% higher than that of exclusive breast-feeding (B Lande, personal communication). Accordingly, the data on exclusive and full breast-feeding in the two studies can be compared, even if the terms have been defined slightly differently. The only material difference in breast-feeding prevalence between SPEDKOST and MoBa can be observed at 6 months: SPEDKOST shows $7 \%$ exclusive breast-feeding while MoBa shows only $2 \cdot 1 \%$ full 
Table 4 Health service-related factors and cessation of full breast-feeding in mothers still breast-feeding between 1 and 3 months after birth (total $n$ 23 972), Norwegian Mother and Child Cohort Study, 2002-2005

\begin{tabular}{|c|c|c|c|c|c|c|c|}
\hline & \multirow[b]{2}{*}{$n$} & \multicolumn{2}{|c|}{ Cessation of full breast-feeding } & \multirow[b]{2}{*}{ Crude RR } & \multirow[b]{2}{*}{$95 \% \mathrm{Cl}$} & \multirow[b]{2}{*}{ Adjusted RR* } & \multirow[b]{2}{*}{$95 \% \mathrm{Cl}$} \\
\hline & & $n$ & $\%$ & & & & \\
\hline \multicolumn{8}{|l|}{ Infant feeding first week } \\
\hline Only breast milk & 18570 & 2627 & $14 \cdot 1$ & $1 \cdot 00$ & Reference & $1 \cdot 00$ & Reference \\
\hline Breast milk and water & 1310 & 232 & $17 \cdot 7$ & $1 \cdot 25$ & $1 \cdot 11,1 \cdot 41$ & $1 \cdot 29$ & $1 \cdot 14,1 \cdot 45$ \\
\hline Breast milk and sugar water & 1471 & 334 & $22 \cdot 7$ & $1 \cdot 61$ & $1 \cdot 45,1 \cdot 78$ & $1 \cdot 48$ & $1 \cdot 34,1 \cdot 64$ \\
\hline Breast milk and formulał & 2621 & 472 & $18 \cdot 0$ & $1 \cdot 27$ & $1 \cdot 16,1 \cdot 39$ & $1 \cdot 18$ & $1 \cdot 07,1 \cdot 29$ \\
\hline \multicolumn{8}{|l|}{ Delivery method } \\
\hline Vaginal & 21200 & 3132 & $14 \cdot 8$ & $1 \cdot 00$ & Reference & $1 \cdot 00$ & Reference \\
\hline Caesarean section & 2772 & 553 & $19 \cdot 2$ & $1 \cdot 29$ & $1 \cdot 19,1 \cdot 40$ & $1 \cdot 15$ & $1 \cdot 06,1 \cdot 25$ \\
\hline \multicolumn{8}{|l|}{ Breast-feeding problems first month } \\
\hline No & 21245 & 3206 & $15 \cdot 1$ & $1 \cdot 00$ & Reference & $1 \cdot 00$ & Reference \\
\hline Yes & 2727 & 459 & $16 \cdot 8$ & $1 \cdot 12$ & $1 \cdot 02,1 \cdot 22$ & $1 \cdot 09$ & $0 \cdot 99,1 \cdot 19$ \\
\hline \multicolumn{8}{|l|}{ Transfer to NICU } \\
\hline No & 20527 & 3084 & $15 \cdot 0$ & $1 \cdot 00$ & Reference & $1 \cdot 00$ & Reference \\
\hline Yes & 1749 & 324 & $18 \cdot 5$ & $1 \cdot 23$ & $1 \cdot 10,1 \cdot 37$ & 0.96 & $0 \cdot 85,1 \cdot 08$ \\
\hline Unknown & 1696 & 257 & $15 \cdot 2$ & $1 \cdot 01$ & $0 \cdot 90,1 \cdot 13$ & 0.98 & $0 \cdot 86,1 \cdot 11$ \\
\hline \multicolumn{8}{|l|}{ Size of institution (births per year) } \\
\hline$<500 \S$ & 2965 & 488 & $16 \cdot 5$ & $1 \cdot 00$ & Reference & $1 \cdot 00$ & Reference \\
\hline 500-1499 & 6269 & 1007 & $16 \cdot 1$ & 0.98 & $0.88,1.08$ & $1 \cdot 02$ & $0.91,1 \cdot 13$ \\
\hline 1500-2999 & 4518 & 676 & $15 \cdot 0$ & 0.91 & $0 \cdot 82,1 \cdot 01$ & $1 \cdot 02$ & $0.90,1 \cdot 17$ \\
\hline$>3000$ & 6323 & 915 & $14 \cdot 5$ & 0.88 & $0.79,0.97$ & $1 \cdot 05$ & $0.93,1.19$ \\
\hline Unknown & 3897 & 579 & $14 \cdot 9$ & 0.90 & $0 \cdot 81,1 \cdot 01$ & $1 \cdot 58$ & $0.97,2.59$ \\
\hline
\end{tabular}

RR, relative risk; NICU, neonatal intensive care unit.

${ }^{*}$ Adjusted for the other variables in the table and maternal age, maternal education, smoking during pregnancy, marital status, region of birth, household income, birth year, pre-pregnancy BMI, parity, sex of the infant, birth weight and plurality.

tSugar water could include water.

¥Formula-fed could include sugar and/or water.

§lncluding 207 births outside institution.

Table 5 Health service-related factors and cessation of full breast-feeding in mothers still breast-feeding between 3 and 6 months after birth (total $n$ 19 080), Norwegian Mother and Child Cohort Study, 2002-2005

\begin{tabular}{|c|c|c|c|c|c|c|c|}
\hline & \multirow[b]{2}{*}{$n$} & \multicolumn{2}{|c|}{ Cessation of full breast-feeding } & \multirow[b]{2}{*}{ Crude RR } & \multirow[b]{2}{*}{$95 \% \mathrm{Cl}$} & \multirow[b]{2}{*}{ Adjusted RR* } & \multirow[b]{2}{*}{$95 \% \mathrm{Cl}$} \\
\hline & & $n$ & $\%$ & & & & \\
\hline \multicolumn{8}{|l|}{ Infant feeding first week } \\
\hline Only breast milk & 14969 & 14477 & $96 \cdot 7$ & $1 \cdot 00$ & Reference & $1 \cdot 00$ & Reference \\
\hline Breast milk and water & 1034 & 1014 & $98 \cdot 1$ & $1 \cdot 01$ & $1 \cdot 00,1 \cdot 02$ & $1 \cdot 01$ & $1 \cdot 00,1 \cdot 02$ \\
\hline Breast milk and sugar watert & 1067 & 1049 & $98 \cdot 3$ & $1 \cdot 02$ & $1 \cdot 01,1 \cdot 03$ & $1 \cdot 02$ & $1.01,1.02$ \\
\hline Breast milk and formulał & 2010 & 1945 & $96 \cdot 8$ & $1 \cdot 00$ & $0.99,1.01$ & $1 \cdot 00$ & $0.99,1.01$ \\
\hline \multicolumn{8}{|l|}{ Delivery method } \\
\hline Vaginal & 17017 & 16508 & $97 \cdot 0$ & $1 \cdot 00$ & Reference & $1 \cdot 00$ & Reference \\
\hline Caesarean section & 2063 & 1977 & $95 \cdot 8$ & 0.99 & $0.98,1.00$ & 0.99 & $0.98,1.00$ \\
\hline \multicolumn{8}{|l|}{ Breast-feeding problems first month } \\
\hline No & 16978 & 16448 & $96 \cdot 9$ & $1 \cdot 00$ & Reference & $1 \cdot 00$ & Reference \\
\hline Yes & 2102 & 2037 & $96 \cdot 9$ & $1 \cdot 00$ & $0.99,1.01$ & $1 \cdot 00$ & $0.99,1.00$ \\
\hline \multicolumn{8}{|l|}{ Transfer to NICU } \\
\hline No & 16441 & 15943 & $97 \cdot 0$ & $1 \cdot 00$ & Reference & $1 \cdot 00$ & Reference \\
\hline Yes & 1291 & 1233 & $95 \cdot 5$ & 0.98 & $0.97,1.00$ & $1 \cdot 00$ & $0.99,1.00$ \\
\hline Unknown & 1348 & 1309 & $97 \cdot 1$ & $1 \cdot 00$ & $0.99,1.01$ & $1 \cdot 00$ & $0.99,1.00$ \\
\hline \multicolumn{8}{|l|}{ Size of institution (births per year) } \\
\hline$<500 \S$ & 2323 & 2251 & $96 \cdot 9$ & $1 \cdot 00$ & Reference & $1 \cdot 00$ & Reference \\
\hline 500-1499 & 4942 & 4786 & $96 \cdot 8$ & $1 \cdot 00$ & $0.99,1.01$ & $1 \cdot 00$ & $0.99,1.00$ \\
\hline 1500-2999 & 3596 & 3487 & $97 \cdot 0$ & $1 \cdot 00$ & $0.99,1.01$ & $1 \cdot 00$ & $0.99,1.00$ \\
\hline$>3000$ & 5096 & 4927 & $96 \cdot 7$ & $1 \cdot 00$ & $0.99,1.01$ & $1 \cdot 00$ & $0.98,1.00$ \\
\hline Unknown & 3123 & 3034 & $97 \cdot 2$ & $1 \cdot 00$ & $0.99,1.01$ & $1 \cdot 00$ & $0.94,1.07$ \\
\hline
\end{tabular}

RR, relative risk; NICU, neonatal intensive care unit.

${ }^{*}$ Adjusted for the other variables in the table and maternal age, maternal education, smoking during pregnancy, marital status, region of birth, household income, birth year, pre-pregnancy BMI, parity, sex of the infant, birth weight and plurality.

tSugar water could include water.

‡Formula-fed could include sugar and/or water.

§lncluding 207 births outside institution.

breast-feeding. The lower prevalence at 6 months observed in MoBa may be explained by differences in the questions asked about infant feeding at that point in time.
We observed a large decline in the incidence of full breast-feeding starting at 3 months (Fig. 2). One possible explanation could be that the traditional practice of 
introducing solid food between months 4 and 6 is still in use. The Norwegian health authorities amended its infant feeding advice in 2001, and have since then recommended exclusively breast-feeding during the first 6 months.

The breast-feeding initiation rate of $98.7 \%$ is higher than in most industrial countries, but comparable to other Nordic countries, some European countries and Australia. The proportion of any breast-feeding at 6 months $(80 \cdot 0 \%)$ is among the highest in Europe and the industrialized world ${ }^{(35,36)}$. The proportion of fully breast-fed infants at 4 months (44.0\%) equals the European average, while a rate of $2 \cdot 1 \%$ for fully breast-fed at 6 months seems low compared with other European countries ${ }^{(36)}$. However, differences in data collection, breast-feeding definitions and participant selection make comparison difficult.

Supplementary feeding with water, sugar water or formula during the first week of life was associated with an increased risk of cessation of full breast-feeding during the first month. A sixfold higher risk was observed where the infant received formula (Table 3). A representative survey from the USA reported a strong association between supplementation (formula or/and water) in the maternity unit and not being exclusively breast-fed at week $1^{(37)}$. Moreover, several studies have linked the use of formula during the first week to shorter overall duration of exclusive or full breast-feeding ${ }^{(19,23,38,39)}$.

Perez-Escamilla et al. identified an association between shorter duration of exclusive breast-feeding and prelacteal feeds with water but not feeds with water-based liquids such as tea, juice or sugar water ${ }^{(22)}$. On the other hand, Nylander et al. identified links between supplementation with sugar water and a shorter duration of exclusive breast-feeding ${ }^{(40)}$, where exclusive breastfeeding was defined as in Table 1 ( $G$ Nylander, personal communication). In our study we also found an association between supplementation with formula, water or sugar water during the first week and cessation of full breast-feeding between 1 and 3 months (Table 4). This suggests a late effect on cessation of full breast-feeding of supplementation during the first week. To the best of our knowledge, such late associations have not been described previously. In a Spanish study, no differences were found regarding the introduction of formula at $8,12,16$ and 20 weeks when a group receiving sugar water as a supplement was compared with a control group receiving no supplementation ${ }^{(20)}$.

The associations between cessation of full breastfeeding and supplementation with water or sugar water remained statistically significant in the time interval 3-6 months, but were very weak and thus of no clinical relevance (Table 5).

One feasible explanation for the associations between supplementation during the first week of life and cessation of full breast-feeding reported here is that supplementation during the first week is an indicator of delayed lactogenesis or problems with the initiation of breast-feeding not reported or included in our category of breast-feeding problems. Alternatively, supplementation during the first week may disturb the normal lactation physiology, and lead to reduced milk production and cessation of full breast-feeding. The associations may also be explained by unknown factors.

In the present study we did not obtain any information about the amount of formula administered, any reason why supplement was given or the frequency of its use. It has been reported that the increased risk of cessation of full breast-feeding associated with formula supplementation can be modified by altering the frequency of supplementation ${ }^{(21)}$. Supplementation with infant formula may also occur when maternal motivation to breastfeed exclusively is lacking.

Avoidance of supplementation without medical indication is one step in the WHO/UNICEF ten steps for a Baby-Friendly Hospital Initiative $(\mathrm{BFHI})^{(41)}$. This is an important tool for reducing unnecessary supplementation by promoting early breast-feeding, feeding on demand, rooming-in and avoiding the use of a pacifier ${ }^{(19,37,42,43)}$. Today, the majority of infants born in Norway are born in a BFHI-designated hospital. Nevertheless, $29.5 \%$ of the infants in our study were not exclusively breast-fed during the first week of life. However, this figure is low compared with other European countries and the USA, where $63-70 \%$ of infants receive supplements in the maternity units ${ }^{(37,38,43)}$.

The question arises whether there are medical reasons for introducing supplements to nearly one-third of the infants in our study sample. Supplementation for medical reasons has been reported to have no influence on duration of exclusive breast-feeding ${ }^{(39)}$, although nonmedical reasons are reported to be the most common cause of supplementation ${ }^{(21,23,26)}$. Water has no nutritional value and there is no medical indication for use, while sugar water may include glucose polymers given as a treatment for hypoglycaemia. Supplementation with formula may have health implications for the infant (related to early introduction of foreign proteins to the mucosa/gut) and should, according to $\mathrm{WHO}$, be considered only when indications are convincing ${ }^{(44,45)}$.

We found that CS was associated with a higher risk of cessation of full breast-feeding during the first month (Table 3) and between months 1 and 3 (Table 4). This is in line with several previous studies ${ }^{(26,28,46)}$. CS has also been associated with delayed initiation of breast-feeding and late onset of lactation ${ }^{(47-49)}$. However, not all studies have found an association between CS and cessation of full breast-feeding shortly after birth, or between CS and a shorter overall duration of exclusive breastfeeding ${ }^{(23,24,27,50)}$. The results of studies are difficult to compare regarding the association between CS and breast-feeding due to differing CS delivery rates and postdelivery practices. In Norway, CS is predominantly used in connection with medical and obstetric high-risk 
conditions, and not upon maternal request. The CS rate in the present study was $12.9 \%$ while the national CS rate in Norway is approximately $15 \%^{(51)}$. CS has been described as an obstacle to early breast-feeding initiation also in BFHI-designated hospitals, and separation of mothers and infants after CS should be avoided when possible and uninterrupted and prolonged skin-to-skin contact should be facilitated after birth ${ }^{(47)}$.

In the present study, $12.9 \%$ of the mothers reported breast-feeding problems during the first month. These included mastitis, sore nipples and other undefined breastfeeding problems (Table 3). The breast-feeding problems were of such severity that health personnel were contacted. Breast-feeding problems were associated with a higher risk of cessation of full breast-feeding during the first month (Table 3). Studies that have examined the association between various breast-feeding problems (such as poor latch-on or nipple problems) have observed a shorter duration of exclusive or full breast-feeding during the first 6 months $^{(24,25,27)}$. Severe breast-feeding problems are almost always very painful, and may lead to cessation of full breast-feeding due to poor latch-on and consequent reduced milk production. However, our results showed that if mothers succeeded in breast-feeding fully during the first month despite experiencing breast-feeding problems, there was no associated increased risk of cessation of full breast-feeding during later time intervals. This supports the concept of a critical period during the first few weeks after birth during which breast-feeding women require more intensive follow-up and support.

There was a lower risk of cessation of full breastfeeding by the end of the first month when the infant was transferred to an NICU after birth (Table 3). This may be explained by the high prevalence of milk banks in Norway and the corresponding high use of human milk, especially for infants with birth weights of less than $1500 \mathrm{~g}^{(9,52)}$. Mothers may also be more concerned about full breast-feeding when the infant is ill immediately after birth. Alternatively, these mothers may receive more help with breast-feeding.

\section{Conclusions}

Despite almost universal initiation of breast-feeding and a high proportion of breast-feeding, very few mothers reported full breast-feeding at 6 months in this large cohort of Norwegian women. The most pronounced decline in full breast-feeding occurred between months 3 and 4. Supplementary feeding with water, sugar water or formula during the first week, CS and breast-feeding problems were associated with cessation of full breastfeeding during the first month. Associations were also observed between cessation of full breast-feeding between months 1 and 3 and supplementation during the first week and CS.
In the context of the WHO guidelines to exclusively breast-feed for 6 months, our results suggest that supplementary feeding with water, sugar water or formula during the first week, breast-feeding problems and CS should be used as indicators for giving breast-feeding mothers extra support and follow-up during hospital stay and after discharge. These findings also support a restrictive approach to supplementation during the first week of life and warrant further study of the necessity of such supplementation.

\section{Acknowledgements}

The MoBa Study was supported by the Norwegian Ministry of Health, the National Institutes of Health/National Institute of Environmental Health Sciences (grant no. N01-ES-85433), the National Institutes of Health/National Institute of Neurological Disorders and Stroke (grant no. 1 UO1 NS 047537-01) and the Norwegian Research Council/ Functional Genomics (grant no. 151918/S10). The authors declare that they have no competing interests. All authors have made a substantial contribution to the study concept and design. A.-P.H. is the main author and performed the statistical analyses in collaboration with A.L.B. A.M.G. was responsible for the statistical analysis. All authors contributed to drafting and critically revised the manuscript. Laura Haiek is acknowledged for her valuable reading of the final manuscript.

\section{References}

1. Agency for Healthcare Research and Quality, US Department for Health and Human Services (2007) Breastfeeding and Maternal and Infant Health Outcomes in Developed Countries, Structured Abstract. Rockville, MD: DHHS.

2. Gartner LM, Morton J, Lawrence RA et al.; American Academy of Pediatrics Section of Breastfeeding (2005) Breastfeeding and the use of human milk. Pediatrics 115, 496-506.

3. World Health Organization (2002) Infant and Young Child Nutrition. Global Strategy on Infant and Young Child Feeding. A55/15, Fifty-fifth World Health Assembly. Geneva: WHO.

4. Stuebe AM \& Schwarz EB (2010) The risks and benefits of infant feeding practices for women and their children. J Perinatol 30, 155-162.

5. Duijts L, Ramadhani MK \& Moll HA (2009) Breastfeeding protects against infectious diseases during infancy in industrialized countries. A systematic review. Matern Child Nutr $\mathbf{5}$, 199-210.

6. Kramer MS \& Kakuma R (2004) The optimal duration of exclusive breastfeeding: a systematic review. Adv Exp Med Biol 554, 63-77.

7. Kramer MS \& Kakuma R (2002) Optimal duration of exclusive breastfeeding. Cochrane Database Syst Rev issue 1, CD003517; available at http://mrw.interscience. wiley.com/cochrane/clsysrev/articles/CD003517/frame.html

8. Chantry CJ, Howard CR \& Auinger P (2006) Full breastfeeding duration and associated decrease in respiratory tract infection in US children. Pediatrics 117, 425-432.

9. Rønnestad A, Abrahamsen TG, Medbø S et al. (2005) Lateonset septicemia in a Norwegian national cohort of 
extremely premature infants receiving very early full human milk feeding. Pediatrics 115, e269-e276.

10. Meinzen-Derr J, Poindexter B, Wrage L et al. (2009) Role of human milk in extremely low birth weight infants' risk of necrotizing enterocolitis or death. J Perinatol 29, 57-62.

11. Quigley MA, Henderson G, Anthony MY et al. (2007) Formula milk versus donor breast milk for feeding preterm or low birth weight infants. Cochrane Database Syst Rev issue 4, CD002971; available at http://mrw.interscience. wiley.com/cochrane/clsysrev/articles/CD002971/frame.html

12. World Health Organization (2007) Evidence of the Longterm Effects of Breastfeeding. Systematic Reviews and Metaanalyses. WHO/NHD/01.08. Geneva: WHO; available at http://whqlibdoc.who.int/publications/2007/ 9789241595230_eng.pdf

13. Yngve A \& Sjöström M (2001) Breastfeeding in countries of the European Union and EFTA: current and proposed recommendations, rationale, prevalence, duration and trends. Public Health Nutr 4, 631-645.

14. Rogers IS, Emmett PM \& Golding J (1997) The incidence and duration of breast feeding. Early Hum Dev 49, Suppl., S45-S74.

15. Dennis CL (2002) Breastfeeding initiation and duration: a 1990-2000 literature review. J Obstet Gynecol Neonatal Nurs 31, 12-32.

16. Scott JA \& Binns CW (1999) Factors associated with the initiation and duration of breastfeeding: a review of the literature. Breastfeed Rev 7, 5-16.

17. Norwegian Directorate for Health (2001) Infant Feeding Recommendations. Oslo: Norwegian Directorate for Health; available at http://www.helsedirektoratet.no/vp/ multimedia/archive/00001/IS-1019_1971a.pdf

18. Norwegian Directorate for Health, University of Oslo \& Norwegian Food Safety Authority (2008) The Norwegian Infant Nutrition Survey Among Six Months Old Infants, 2006-2007. Oslo: Norwegian Directorate for Health, University of Oslo \& Norwegian Food Safety Authority; available at http://www.helsedirektoratet.no/vp/multimedia/ archive/00054/IS-1535_54649a.pdf

19. Merten S, Dratva J \& Ackermann-Liebrich U (2005) Do baby-friendly hospitals influence breastfeeding duration on a national level? Pediatrics 116, e702-e708.

20. Martin-Calama J, Bunuel J, Valero MT et al. (1997) The effect of feeding glucose water to breastfeeding newborns on weight, body temperature, blood glucose, and breastfeeding duration. J Hum Lact 13, 209-213.

21. Howard CR, Howard FM, Lanphear B et al. (2003) Randomized clinical trial of pacifier use and bottle-feeding or cupfeeding and their effect on breastfeeding. Pediatrics 111, 511-518.

22. Perez-Escamilla R, Segura-Millan S, Canahuati J et al. (1996) Prelacteal feeds are negatively associated with breast-feeding outcomes in Honduras. J Nutr 126, $2765-2773$.

23. Alikasifoglu M, Erginoz E, Gur ET et al. (2001) Factors influencing the duration of exclusive breastfeeding in a group of Turkish women. J Hum Lact 17, 220-226.

24. Cernadas JM, Noceda G, Barrera L et al. (2003) Maternal and perinatal factors influencing the duration of exclusive breastfeeding during the first 6 months of life. J Hum Lact 19, 136-144.

25. Santo LC, de Oliveira LD \& Giugliani ER (2007) Factors associated with low incidence of exclusive breastfeeding for the first 6 months. Birth 34, 212-219.

26. Kurinij N \& Shiono PH (1991) Early formula supplementation of breast-feeding. Pediatrics 88, 745-750.

27. Scott JA, Binns CW, Oddy WH et al. (2006) Predictors of breastfeeding duration: evidence from a cohort study. Pediatrics 117, e646-e655.
28. Cattaneo A \& Buzzetti R (2001) Effect on rates of breast feeding of training for the baby friendly hospital initiative. BMJ 323, 1358-1362.

29. Magnus P, Irgens LM, Haug K et al. (2006) Cohort profile: The Norwegian Mother and Child Cohort Study (MoBa). Int J Epidemiol 35, 1146-1150.

30. Irgens LM (2000) The Medical Birth Registry of Norway. Epidemiological research and surveillance throughout 30 years. Acta Obstet Gynecol Scand 79, 435-439.

31. Bland JM \& Altman DG (2000) Statistics notes. The odds ratio. BMJ 320, 1468.

32. Bland RM, Rollins NC, Solarsh G et al. (2003) Maternal recall of exclusive breast feeding duration. Arch Dis Child 88, 778-783.

33. Nilsen RM, Vollset SE, Gjessing HK et al. (2009) Selfselection and bias in a large prospective pregnancy cohort in Norway. Paediatr Perinat Epidemiol 23, 597-608.

34. Lande B, Andersen LF, Baerug A et al. (2003) Infant feeding practices and associated factors in the first six months of life: the Norwegian infant nutrition survey. Acta Paediatr 92, 152-161.

35. Callen J \& Pinelli J (2004) Incidence and duration of breastfeeding for term infants in Canada, United States, Europe, and Australia: a literature review. Birth 31, 285-292.

36. Cattaneo A, Yngve A, Koletzko B et al. (2005) Protection, promotion and support of breast-feeding in Europe: current situation. Public Health Nutr 8, 39-46.

37. Declercq E, Labbok MH, Sakala C et al. (2009) Hospital practices and women's likelihood of fulfilling their intention to exclusively breastfeed. Am J Public Health 99, 929-935.

38. Riva E, Banderali G, Agostoni C et al. (1999) Factors associated with initiation and duration of breastfeeding in Italy. Acta Paediatr 88, 411-415.

39. Ekström A, Widström AM \& Nissen E (2003) Duration of breastfeeding in Swedish primiparous and multiparous women. J Hum Lact 19, 172-178.

40. Nylander G, Lindemann R, Helsing E et al. (1991) Unsupplemented breastfeeding in the maternity ward. Positive long-term effects. Acta Obstet Gynecol Scand 70, 205-209.

41. World Health Organization (1989) Protecting, Promoting and Supporting Breastfeeding: The Special Role of Maternity Services. Geneva: WHO; available at http://lib.store. yahoo.net/lib/babyinc-store/PromotingBreastfeeding.pdf

42. Giovannini M, Riva E, Banderali G et al. (2005) Exclusive versus predominant breastfeeding in Italian maternity wards and feeding practices through the first year of life. J Hum Lact 21, 259-265.

43. Merten S \& Ackermann-Liebrich U (2004) Exclusive breastfeeding rates and associated factors in Swiss babyfriendly hospitals. J Hum Lact 20, 9-17.

44. Weaver LT, Laker MF, Nelson R et al. (1987) Milk feeding and changes in intestinal permeability and morphology in the newborn. J Pediatr Gastroenterol Nutr 6, 351-358.

45. Catassi C, Bonucci A, Coppa GV et al. (1995) Intestinal permeability changes during the first month: effect of natural versus artificial feeding. J Pediatr Gastroenterol Nutr 21, 383-386.

46. Khassawneh M, Khader Y, Amarin Z et al. (2006) Knowledge, attitude and practice of breastfeeding in the north of Jordan: a cross-sectional study. Int Breastfeed J 1, 17.

47. Rowe-Murray HJ \& Fisher JR (2002) Baby friendly hospital practices: cesarean section is a persistent barrier to early initiation of breastfeeding. Birth 29, 124-131.

48. Chapman DJ \& Perez-Escamilla R (1999) Identification of risk factors for delayed onset of lactation. J Am Diet Assoc 99, 450-454. 
49. Dewey KG, Nommsen-Rivers LA, Heinig MJ et al. (2003) Risk factors for suboptimal infant breastfeeding behavior, delayed onset of lactation, and excess neonatal weight loss. Pediatrics 112, 607-619.

50. Chung W, Kim H \& Nam CM (2008) Breast-feeding in South Korea: factors influencing its initiation and duration. Public Health Nutr 11, 225-229.

51. Tollanes MC, Moster D, Daltveit AK et al. (2008) Cesarean section and risk of severe childhood asthma: a populationbased cohort study. J Pediatr 153, 112-116.
52. Grøvslien AH \& Grønn M (2009) Donor milk banking and breastfeeding in Norway. J Hum Lact 25, 206-210.

53. World Health Organization (1991) Indicators for Assessing Breastfeeding Practices. WHO/CDD/SER 91.14. Geneva: WHO; available at http://www.emro.who.int/CAH/pdf/ bf_indicators.pdf

54. World Health Organization (2008) Indicators for Assessing Infant and Young Child Feeding Practices. Part 1: Definitions. Geneva: WHO; available at http://whqlibdoc. who.int/publications/2008/9789241596664_eng.pdf 